\title{
Survey of malaria and anti-dengue virus IgG among febrile HIV-infected patients attending a tertiary hospital in Abuja, Nigeria
}

This article was published in the following Dove Press journal:

HIVIAIDS - Research and Palliative Care

30 June 2017

Number of times this article has been viewed

Jelili Olaide Mustapha' Anthony Uchenna Emeribe ${ }^{2}$ Idris Abdullahi Nasir ${ }^{3}$

'Department of Medical Microbiology, Lagos State University Teaching Hospital, Ikeja, Lagos, ${ }^{2}$ Department of Medical Laboratory Science, University of Calabar, Calabar, Cross River State, ${ }^{3}$ Department of Medical Laboratory Services, University of Abuja Teaching Hospital, FCT Abuja, Nigeria
Correspondence: Anthony Uchenna Emeribe

Department of Medical Laboratory Science, University of Calabar, PMB 3722, Calabar, Cross River State, Nigeria Email uemeribe@yahoo.com
Background: Dengue and malaria are infections, of great public health concern, especially in sub-Saharan Africa where the burden of HIV infection is high. This study was conducted to determine the seroprevalence of dengue virus IgG antibodies and dengue/malaria coinfection among febrile HIV-infected patients attending the University of Abuja Teaching Hospital, Gwagwalada, Abuja.

Methods: In this cross-sectional study, blood samples from 178 consenting HIV-infected patients receiving antiretroviral therapy were collected and tested for plasmodiasis and anti-Dengue virus IgG using malaria microscopy and ELISA, respectively. Interviewer-based questionnaires were used to assess subjects' sociodemographic variables and dengue risk factors.

Results: Of the 178 screened participants, $44.4 \%$ were seropositive for dengue virus IgG antibody, whereas $29.2 \%$ were positive for Plasmodium falciparum. About $44.2 \%$ were positive for both dengue virus and $P$. falciparum. There was a statistical association between anti-dengue IgG and occupation ( $p=0.03$ ) but not with age, residential area, educational level and patients' gender $(p>0.05)$. Seroprevalence of anti-dengue specific IgG was relatively higher in participants who adopted protective measures. There was a statistical association between seroprevalence of anti-dengue $\mathrm{IgG}$ and adoption of preventive measures $(p<0.05)$.

Conclusion: The high prevalence of malaria and dengue virus IgG indicates the need to strengthen vector control and dengue surveillance programs.

Keywords: coinfection, seroprevalence, flavivirus, sydemism

\section{Introduction}

Dengue is the most common arthropod-borne and neglected tropical viral disease which affects over 2.5 billion people at risk of infection worldwide. ${ }^{1}$ Dengue is an infection caused by positive sense, single-stranded RNA viruses of the Flaviviridae family. ${ }^{2,3}$ The dengue virus serotypes 1-4 (DENV 1-4), which are the causative strains in the pathogenesis of dengue, ${ }^{2}$ are transmitted by Aedes mosquitoes, mainly by Aedes aegypti and Aedes albopictus. ${ }^{3}$ Malaria is another mosquito-borne disease with severe effects in HIV-infected persons. The clinical manifestations of dengue have several similitudes with those of malaria. ${ }^{4}$ In malaria and dengue coinfection cases, they abruptly lead to a syndemic outcome. However, in people living with HIV, milder pathology is noticed.

Dengue is endemic in tropical and subtropical parts of the world where there is high prevalence of HIV infection. ${ }^{2}$ Although several studies have shown varying prevalences in different parts of Nigeria, there is paucity in the number of reported cases in Nigeria due to a dearth of information about the infection by health care 
professionals and lack of prioritization as well as apathy toward investing in dengue research by relevant stakeholders in the public health sector. ${ }^{5}$

The dengue virus has been considered an important flavivirus that exhibits a protective role against HIV by transiently inhibiting its replication. Coincidentally, all four serotypes of DENV circulate in Nigeria. DENV and HIV coinfection would be an important factor for delayed progression to AIS. In DENV infection, responses by the immune system result in protection against the virus and pathogenesis of the severe form of the disease. ${ }^{6}$ Several cytokines (tumor necrosis factor, IL-1, IL-21, interferon) in innate immunity, produced by CD4+ T cells, have been associated with the pathogenesis of DENV infection, which is suggestive of their protective role in the acute stage of secondary DENV infection and the convalescence stage of primary DENV infection. Immunity against DENV infection is conferred by activating innate and adaptive immune cells, chemotaxis and inhibition of viral replication. ${ }^{6}$ However, high levels of cytokine response also lead to apoptosis and necrosis, endothelial activation, vascular leak and shock.

According to Gonzalez et al, ${ }^{7}$ patients with DENV-HIV coinfection are likely to have acute clinical illnesses with no increase in dengue hemorrhagic fever (DHF) and dengue shock syndrome. Watt et al ${ }^{8}$ suggested that DENV could attribute to a protective role against HIV-1 by transiently inhibiting its replication during acute DENV infection. McLinden et $\mathrm{al}^{9}$ and Xiang et $\mathrm{al}^{10}$ speculated that the suppressed replication of HIV in HIV-DENV-coinfected patients could be due to the role of the DENV NS5 protein downregulating the HIV coreceptor (CXCR4) expression and elevated synthesis of stromal cell-derived factor 1 (SDF-1). Nevertheless, these cases cannot be used to conclude that there will not be an increased risk of severe disease in DENV-HIV-coinfected patients.

Dengue fever is clinically difficult to diagnose, especially in developing countries with no established dengue diagnostic reagents/equipment, and could easily be mistaken for malaria, typhoid or pyrexia of unknown origin due to frequent nonspecific illnesses exhibited by HIV-infected individuals. ${ }^{4}$ However, there is paucity of research on the clinical presentations and outcomes of dengue infection in HIV-infected persons. This study was conducted to determine the seroprevalence of dengue virus IgG antibodies and dengue/malaria coinfection among febrile HIV-infected patients attending a tertiary hospital, Gwagwalada, Abuja.

\section{Materials and methods}

\section{Study area and design}

This was a cross-sectional study conducted at the University of Abuja Teaching Hospital (UATH), Gwagwalada, Federal Capital Territory (FCT)-Abuja, Nigeria. Gwagwalada is about $45 \mathrm{~km}$ from the FCT. It is one of the six area council headquarters of the FCT. The town lies downstream of River Usuma and is located between latitudes $8^{\circ} 55^{\prime}$ and $9^{\circ} 00^{\prime} \mathrm{N}$ and longitudes $7^{\circ} 00^{\prime}$ and $7^{\circ} 05^{\prime} \mathrm{E}$.

\section{Informed consent and ethical approval}

Ethical approval (FCT/UATH/HREC/PR/571) was obtained from the ethical research committee of the University of Abuja Teaching Hospital, Gwagwalada, FCT-Abuja. For the study, we enrolled patients that provided their written consent to voluntarily participate, were sero-positive for HIV and on antiretroviral therapy and presented with febrile illnesses regardless of onset and duration of illness. We excluded patients who were nonfebrile, critically ill, seronegative for HIV or seropositive for HIV and not on antiretroviral therapy drugs.

\section{Study population}

A total of 178 HIV-infected patients seeking medical assistance at the UATH were enrolled in the study and were designated test subjects. The selection of all participants was conducted by physicians and nursing staff of the PEPFAR (President's Emergency Plan for AIDS Relief) clinic, UATH, Abuja. Informed consent was obtained from all participants in accordance with the standards of human experimentation and with the Helsinki Declaration of 1975 as adopted by the World Medical Association. ${ }^{11}$

Prior to this study, there has never been a similar study in Nigeria; hence, the sample size was determined using the equation derived by Naing et al, ${ }^{12}$ and the prevalence was estimated by using the 2012 national HIV prevalence rate, $3.4 \% .{ }^{13}$ Therefore, the minimum sample size at $95 \%$ confidence level was 51 . However, in order to enhance the statistical reliability of the study, the sample size was increased to 178 participants.

\section{Methods}

\section{Sample collection and storage}

A sample of $3 \mathrm{~mL}$ of blood was collected from each participant using a standard venepuncture procedure. The blood was carefully and gently dispensed into sterile, plain, sample containers. The tubes were labelled appropriately with the participants' 
identification numbers. Sera from these blood samples were separated by allowing the blood to clot at room temperature before centrifuging at $2500 \mathrm{rpm}$ for $10 \mathrm{~min}$. Thereafter, the retracted sera were dispensed into serum aliquot containers and stored at $-10^{\circ} \mathrm{C}$ pending laboratory analyses.

\section{Detection of malaria parasite and speciation}

Thick and thin blood films were made, stained with $10 \%$ Giemsa and microscopically examined to detect malaria parasites and identify their species, respectively, as described by McKenzie et al. ${ }^{14}$

Determination of IgG antibodies against dengue virus The IgG to dengue fever virus was detected in the serum using commercial ELISA kits (Anti-Dengue virus Euroimmun ${ }^{\mathrm{TM}}$ IgG ELISA Kits, Lueback, Germany [Catalog Number EQ-266a-9601 G]). The assay was performed based on the manufacturer's instructions.

\section{Result interpretation}

Samples with ratios of $\geq 1.1$ in relation to the optical density of standard 2 of the kit were reported as positive, while negative samples were those with ratios $<0.8$ in relation to the optical density of standard 2 .

\section{Data analysis}

Results generated from analysis and data obtained from the questionnaire were analyzed using the Statistical Package for Social Sciences (SPSS) version 20 (IBM Corporation, Armonk, NY, USA). The chi-square test was used to determine the level of significance in the occurrence of malaria parasitemia and dengue virus IgG in association with categorized variables at a CI of $95 \%$. $p$-values were reported to be statistically significant at $<0.05$.

\section{Results}

Out of 178 samples studied, 79 (prevalence of $44.4 \%$ ) were seropositive for dengue virus IgG and 23 of the 79 (prevalence of $44.2 \%$ ) were coinfected with dengue virus and malaria parasites (Table 1). The prevalence of malaria in this study is $29.2 \%$. All malaria parasites were $P$. falciparum.

Based on demographic factors, 51 of the 79 positive cases for dengue virus IgG were female participants with a prevalence of $49.0 \%(51 / 104)$, which was higher than that of their male counterparts with a seroprevalence of $37.8 \%$ (28/74). Seropositivity was observed to increase from participants who were within the age range of $21-30$ years $(36.8 \%$ : $21 / 57$ ) compared to participants who were $\geq 50$ years of age
Table I Seroprevalence of dengue virus $\lg G$ in association with demographic factors among patients attending UATH, Gwagwalada, FCT-Abuja, Nigeria

\begin{tabular}{|c|c|c|c|}
\hline $\begin{array}{l}\text { Sociodemographic } \\
\text { variable }\end{array}$ & $\begin{array}{l}\text { No of } \\
\text { subjects } \\
\text { tested }\end{array}$ & $\begin{array}{l}\text { No of subjects } \\
\text { with anti-DENV } \\
\text { IgG positive (\%) }\end{array}$ & $p$-value \\
\hline \multicolumn{4}{|l|}{ Age range (years) } \\
\hline$\leq 10$ & 21 & $8(38.1)$ & 0.536 \\
\hline $11-20$ & 40 & $20(50.0)$ & \\
\hline $21-30$ & 57 & $21(36.8)$ & \\
\hline $31-40$ & 28 & $12(42.9)$ & \\
\hline $4 I-50$ & 22 & $12(54.5)$ & \\
\hline$>50$ & 10 & $6(60.0)$ & \\
\hline \multicolumn{4}{|l|}{ Gender } \\
\hline Male & 74 & $28(37.8)$ & 0.138 \\
\hline Female & 104 & $51(49.0)$ & \\
\hline \multicolumn{4}{|l|}{ Residence } \\
\hline Village & 60 & $26(43.3)$ & $0.84 I$ \\
\hline Suburb & 118 & $53(44.9)$ & \\
\hline \multicolumn{4}{|l|}{ Education } \\
\hline Primary & 37 & II (29.7) & 0.152 \\
\hline Secondary & 45 & $21(46.7)$ & \\
\hline Tertiary & 40 & $17(42.5)$ & \\
\hline No formal education & 56 & $30(53.7)$ & \\
\hline \multicolumn{4}{|l|}{ Occupation } \\
\hline Farmer & 10 & $9(90.0)$ & $0.030 *$ \\
\hline Driver & 18 & 7 (38.9) & \\
\hline Housewife & 35 & $16(45.7)$ & \\
\hline Civil servant & 68 & $31(45.6)$ & \\
\hline Unemployment & 47 & $16(34.0)$ & \\
\hline
\end{tabular}

Note: *Significant for $p<0.05$.

Abbreviations: DENV, dengue virus serotypes; FCT, Federal Capital Territory; UATH, University of Abuja Teaching Hospital.

(60.0\%: 6/10). Regarding occupation, IgG to dengue virus was detected in the highest prevalence of $90.0 \%(9 / 10)$ among farmers, while the lowest prevalence of $34.0 \%$ (16/47) was recorded among the unemployed participants. Unlike other risk factors, statistically significant differences were observed between occupation and the presence of $\mathrm{IgG}$ to dengue virus $\left(X^{2}=10.75 ; d f=4, p=0.030\right)$ (Table 2).

Based on risk factors, 53 out of 138 participants who resided close to refuse dump sites or water collection spots were positive for IgG to dengue virus with a prevalence of $38.4 \%$, while 26 out of 40 participants who resided within a hygienic zone of beyond $500 \mathrm{~m}$ from the waste dump sites were positive for IgG to dengue virus with a prevalence of $65.0 \%$. There was a statistically significant difference between the proximity to waste dump sites and the presence of $\mathrm{IgG}$ to dengue virus $\left(X^{2}=8.89 ; d f=1, p=0.003\right)$ (Table 3$)$. Data generated from the prevention of water exposure indicated that a greater proportion of participants who consistently covered their household water containers were positive for IgG to 
Table 2 Seroprevalence of dengue virus $\lg G$ in association with risk factors among patients attending UATH, Gwagwalada, FCTAbuja, Nigeria

\begin{tabular}{|c|c|c|c|}
\hline Risk factors & $\begin{array}{l}\text { No of subject } \\
\text { tested }\end{array}$ & $\begin{array}{l}\text { No of subjects } \\
\text { with anti-DENV } \\
\text { IgG positive (\%) }\end{array}$ & p-value \\
\hline \multicolumn{4}{|c|}{$\begin{array}{l}\text { Residence in proximity to refuse dumpsite or water } \\
\text { collection spots }\end{array}$} \\
\hline No & 40 & $26(65.0)$ & $0.003^{*}$ \\
\hline Yes & 138 & $53(38.4)$ & \\
\hline \multicolumn{4}{|c|}{ Consistent covering of household water containers } \\
\hline No & 154 & $66(42.9)$ & 0.300 \\
\hline Yes & 24 & $13(54.2)$ & \\
\hline \multicolumn{4}{|c|}{ Frequent wearing of long sleeve shirts and trousers } \\
\hline No & 132 & $52(39.4)$ & $0.023 *$ \\
\hline Yes & 46 & $27(58.7)$ & \\
\hline \multicolumn{4}{|c|}{ Indoor mosquito repellents } \\
\hline No & 148 & $62(41.9)$ & 0.137 \\
\hline Yes & 30 & $17(7 \mid .6)$ & \\
\hline \multicolumn{4}{|c|}{ Frequent use of indoor insecticide sprays } \\
\hline No & 149 & $61(40.9)$ & $0.036 *$ \\
\hline Yes & 29 & $18(62.1)$ & \\
\hline
\end{tabular}

Note: *Significant for $p<0.05$.

Abbreviations: DENV, dengue virus serotypes ; FCT, Federal Capital Territory; UATH, University of Abuja Teaching Hospital.

Table 3 Coinfection of dengue virus and malaria in the study population

\begin{tabular}{lll}
\hline Malaria status & Anti-dengue virus IgG \\
\cline { 2 - 3 } & No of subjects tested & Subjects positive (\%) \\
\hline Negative & 126 & $56(44.4)$ \\
Positive & 52 & $23(44.2)$ \\
Total & 178 & $79(44.4)$ \\
\hline
\end{tabular}

dengue virus with a prevalence of $54.2 \%$, while those who did not cover their household water containers were $42.9 \%$. There was no statistically significant difference between the consistent covering of water containers and the presence of IgG to dengue virus $\left(X^{2}=1.08 ; d f=1, p=0.300\right)$. In terms of the use of protective clothing, IgG to dengue virus was relatively higher in participants who frequently wore long sleeves and trousers with a prevalence of $58.7 \%$ compared to those who less frequently used such clothing with a prevalence of $39.4 \%$. There was a statistically significant difference between the frequent wearing of long sleeves with trousers and the presence of $\operatorname{IgG}$ to dengue virus $\left(X^{2}=5.15 ; d f=1, p=0.023\right)$. The level of IgG to dengue virus was also observed as relatively higher in participants who were exposed to indoor mosquito repellents with a prevalence of $71.6 \%$ compared to those that are not exposed with a prevalence of $41.9 \%$. There was no statistically significant difference between exposure to mosquito repellents, water containers and the presence of IgG to dengue virus $\left(X^{2}=2.206 ; d f=1, p=0.138\right)$. On the frequent use of indoor insecticides, participants who use these chemicals had indications of higher levels of IgG to dengue virus with a prevalence of $62.1 \%$ compared to their counterparts who less frequently used these insecticides with a prevalence of $40.9 \%$. There was a statistically significant difference between the frequent use of indoor insecticides and the presence of IgG to dengue virus $\left(X^{2}=4.39 ; d f=1, p=0.036\right)$.

\section{Discussion}

Recently, dengue fever infection has been considered an emerging public health problem in several African countries with risk of severe infections. ${ }^{15,16}$ Most febrile cases are routinely diagnosed and treated for typhoid and/or malaria without proper investigation for other conditions including viral infections.

The objectives of this study were to determine the seroprevalence and coinfection rate of dengue virus among febrile and HIV patients recruited at the UATH, Gwagwalada, FCTAbuja, Nigeria. Despite Nigeria being among the countries with the most cases of new HIV infection and dengue hyperendemic, there have been no similar studies. This current study reported a prevalence of $44.4 \%$ for dengue-specific IgG antibody among participants, which is in accordance with the findings of Sultana et al, ${ }^{17}$ who observed $42.9 \%$ seroprevalence of anti-dengue IgG in Chittagong, Bangladesh. The seroprevalence from this study is not in conformity with dengue virus-specific IgG seroprevalence of $67.2 \%$ by Mahmood et al, ${ }^{18} 77 \%$ by Adeleke et al, ${ }^{19} 79 \%$ by Peyerl-Hoffmann et $\mathrm{al}^{20}$ and $98 \%$ by Yamashiro et al. ${ }^{21}$ The observed discrepancies in prevalence reports could be due to the level of awareness of dengue, urbanization and environment deterioration. ${ }^{22}$ The high circulation of dengue virus in the study area could be attributed to several factors including misdiagnosis of febrile cases, the movement of migrants from endemic countries and the proliferation of breeding sites of Aedes mosquitoes. ${ }^{23}$ These factors may have enhanced the high circulation of dengue virus in Gwagwalada. The mean total rainfall in this area is $\sim 1650 \mathrm{~mm} /$ annum. About $60 \%$ of this rain falls between May and August during which samples were collected. The area council is an industrial zone of FCT that stands out as the second most cosmopolitan city of the FCT, after the capital city with 10 political wards, and consists of more than 26 federal organizations, which include the University of Abuja, the UATH, etc. These have brought about the inflow of people into the council. About $75 \%$ of Gwagwalada residents live in close proximity to poor drainage system, several potholes on their streets and indiscriminate environmental dumpsites. ${ }^{24}$ This 
often encourages the collection of artificial water containers and, thus, serves as the breeding sites for mosquito vectors of dengue virus infections.

We reported $44.2 \%$ co-occurrence of dengue virus IgG antibodies and malaria parasitemia. This value is closely similar to that reported by Adeleke et a ${ }^{19}$ who reported a dengue IgG and malaria prevalence of 33\% in Osogbo, Southwestern Nigeria; however, this was higher than the seroprevalence of $1.3 \%$ by Idoko et $\mathrm{al}^{25}$ in Kaduna; $2.2 \%$ by Dawurung et $\mathrm{al}^{28}$ in Jos, Plateau State; and $10.1 \%$ by Idris et $\mathrm{al}^{23}$ in Maiduguri, Northern Nigeria. The difference in dengue virus serology as reported by earlier studies with lower prevalence is due to the IgM to dengue virus that was investigated, unlike the present study that investigated only dengue virus IgG. IgM accounts only for current exposure to dengue infections which dissipate, but not completely, with time. However, IgG accounts for both previous and present exposure to dengue virus and appears from 5 to 7 days of infection. Reinfections with the virus could result to pathological IgG titer and severe symptoms including DHF. ${ }^{27}$ The high prevalence of malaria and dengue coinfection in this present study is an indication of poor vector control measures against dengue vector in the community.

Regarding the gender-related prevalence of DENV IgG from this study, more females were being infected than their male counterparts. This observation is in consonance with Bello et $\mathrm{al}^{30}$ and Adeleke et al, ${ }^{19}$ studies but not with others' studies ${ }^{18,20,31,32,33}$ which reported higher prevalence for dengue infection in males than in females. The disparity in the prevalence for gender could be the relatively large number of females recruited for the study compared to fewer males. The females were exposed more to the risk factors such as being engaged in most domestic activities. Since the dengue vector is predominantly indoor biting mosquitoes, ${ }^{29}$ women may be more likely to have a relatively higher prevalence of dengue virus-specific IgG.

There was no association between age and dengue infection, which was in conformity with the report of previous studies. ${ }^{4,30}$ This observation is, however, in contrast to literature by Peyerl-Hoffmann et $\mathrm{al}^{20}$ and Reiskind et al, ${ }^{34}$ who reported an age-dependent increase of anti-dengue antibodies in participants with risk of infections. The prevalence of dengue virus IgG from this study has a significant association with the occupation of participants. Farmers appeared to the group with the highest cases of DENV IgG seropositivity. This agrees with the findings of Bello et $\mathrm{al}^{28}$ and Oladipo et al, ${ }^{35}$ which indicates that farming activities are predisposed to dengue virus infection as a result of sylvatic-to-urban spillover.
Findings from this study indicated a higher prevalence of dengue virus IgG seropositivity in study participants who adopted various protective measures against the vector bites compared to those who did not adhere to such protective measures. In contrast to these observations on the use of protective measures such as using indoor insecticide sprays in preventing the spread of dengue virus, Mahmood et $\mathrm{al}^{18}$ reported a higher dengue burden in participants who never used indoor anti-mosquito sprays compared to those who frequently used such sprays, and their findings indicated no significant association between anti-dengue seropositivity and frequency in the use of these insecticides. Unlike the previous study that recruited apparently healthy adult participants, our study involved the study of immunocompromised participants. Viral infections, generally, suppress the natural immunity of the affected individual, which often predisposes the individual to opportunistic infections. ${ }^{26}$ Therefore, coinfection with dengue virus, HIV, and malaria as observed in this study could be very devastating to the affected participants who are immunosuppressed, thus lacking the ability to mount immune response by producing sufficient serum levels of anti-dengue IgG in the presence of increasing pathogenic burden.

Of the 178 subjects tested, 23 (44.2\%) were malaria patients with anti-dengue IgG positivity. This finding was higher than those of Idoko et $\mathrm{al}^{25}$ and Baba et $\mathrm{al}^{26}$ who reported $1.3 \%$ and $5.8 \%$ malaria/dengue coinfection in Kaduna and Maiduguri cities of Nigeria, respectively. The higher rates of malaria/dengue coinfection from this study could be due to differences in sample size and design, type of laboratory test used, difference in climatic conditions and in malaria and dengue endemicity of these cities. This finding is not surprising, because Anopheles and Aedes mosquitoes have severally been reported to be in existence in Abuja; ${ }^{27}$ therefore, the presence of dengue and malaria in this study is expected. This result is very important because Nigeria is one of the few African countries that limit the investigation of febrile illnesses to malaria and typhoid with complete neglect to viral infections. In general, viral infections suppress the natural immunity of the host, and this often allows opportunistic infections. ${ }^{28}$ Therefore, a coinfection of dengue and malaria as observed in this study could be very devastating to HIV-infected persons. Sustainable vector control should be the paramount technical strategy for malaria and dengue prevention and control. Considering the hyperendemicity of both infections in Nigeria, prevention of mosquito breeding sites and/or bites should be emphasized at all community levels. 


\section{Conclusion}

There exist statistical associations between dengue IgG seropositivity and proximity to waste dump sites, wearing protective clothing and frequent use of indoor insecticide sprays. Our findings provide the baseline data of the level of dengue virus circulating in the study population. These observations seek a prompt and adequate response from the individuals, community and government policy makers to adopt preventive and control measures that can mitigate the resultant effects of morbidity and mortality resulting from dengue burden especially in immunosuppressed individuals.

\section{Acknowledgment}

The authors express their special thanks to Mr Mustapha Bakare and his Intern Medical Laboratory Scientists for their technical input and data extraction from questionnaires.

\section{Disclosure}

The authors report no conflicts of interest in this work.

\section{References}

1. Whitehorn J, Simmons CP. The pathogenesis of dengue. Vaccine. 2011;29(42):7221-7228.

2. Pang J, Thein TL, Lye DC, Leo YS. Differential clinical outcome of dengue infection among patients with and without HIV infection: a matched case-control study. Am J Trop Med Hyg. 2015;92(6):1156-1162.

3. Rioth M, Beauharnais CA, Noel F, et al. Serologic imprint of dengue virus in urban Haiti: characterization of humoral immunity to dengue in infants and young children. Am J Trop Med Hyg. 2011;84(4):630-636.

4. Baba M, Saron MF, Vorndam A, Adeniji J, Diop O, Olaleye D. Dengue virus infections in patients suspected of malaria/typhoid in Nigeria. J Am Sci. 2009;5(5):129-134.

5. Ayukekbong JA. Dengue virus in Nigeria: current status and future perspective. Br J Virol. 2014;1(4):106-111.

6. Vivanco-Cid H, Maldonado-Renteria MJ, Sanchez-Vargas LA, Izaguirre-Hernandez IY, Hernandez-Flores KG, Remes-Ruiz R. Dynamics of interleukin-21 production during the clinical course of primary and secondary dengue virus infections. Immunol Lett. 2014;161(1):89-95.

7. Gonzalez D, Limonta D, Bandera JF, Perez J, Kouri G, Guzman MG. Dual infection with dengue virus 3 and human immunodeficiency virus 1 in Havana, Cuba. J Infect Dev Ctries. 2009;3(4):318-320.

8. Watt G, Kantipong P, Jongsakul K. Decrease in human immunodeficiency virus type 1 load during acute dengue fever. Clin Infect Dis. 2003;36(8):1067-1069.

9. McLinden JH, Stapleton JT, Chang Q, Xiang J. Expression of the dengue virus type 2 NS5 protein in a CD4(+) T cell line inhibits HIV replication. J Infect Dis. 2008;198(6):860-863.

10. Xiang J, McLinden JH, Rydze RA, et al. Viruses within the Flaviviridae decrease CD4 expression and inhibit HIV replication in human CD4+ cells. J Immunol. 2009;183(12):7860-7869.

11. World Medical Association. World Medical Association Declaration of Helsinki: ethical principles for medical research involving human subjects. JAMA. 2013;310(20):2191-2194.

12. Naing L, Winn T, Rusli BN. Practical issues in calculating the sample size for prevalence studies. Arch Orofac Sci. 2006;1:9-14.

13. Federal Ministry of Health [Nigeria]. National HIV \& AIDS and Reproductive Health Survey, 2012 (NARHS Plus). Federal Ministry of Health Abuja, Nigeria; 2013.
14. McKenzie FE, Prudhomme WA, Magill AJ, et al. White blood cell counts and malaria. J Infect Dis. 2005;192(2):323-330.

15. Amarasinghe A, Kuritsk JN, Letson GW, Margolis HS. Dengue virus infection in Africa. Emerg Infect Dis. 2011;17(8):1349-1354.

16. Shepard DS, Undurraga EA, Halasa YA. Economic and disease burden of dengue in Southeast Asia. PLoS Negl Trop Dis. 2013;7(2): e2055.

17. Sultana N, Biswas SK, Sultan T, Ahmed S, Hossein Z, Chaowdhr R. Seroprevalence of dengue fever in Chittagong, Bangladesh. Chattagram Maa-O-Shishu Hosp Med College J. 2013;12(1):38-40.

18. Mahmood S, Nabeel H, Hafeez S, Zahra U, Nazeer H. Seroprevalence of dengue IgG antibodies among healthy adult population in Lahore, Pakistan. ISRN Trop Med. 2013;2013:6.

19. Adeleke MA, Muhibi MA, Ajayi EIO, et al. Dengue virus specific Immunoglobulin $\mathrm{G}$ antibodies among patients with febrile conditions in Oshogbo, South-western Nigeria. Trop Biomed. 2016;33(1):1-7.

20. Peyerl-Hoffmann G, Schwobel B, Jordan S, et al. Serological investigation of the prevalence of anti-dengue $\operatorname{IgM}$ and $\operatorname{IgG}$ antibodies in Attapeu Province, South Laos. Clin Microbiol Infect. 2004;10(2): 181-184.

21. Yamashiro T, Disla M, Petit A, et al. Seroprevalence of IgG specific for dengue virus among adults and children in Santo Domingo, Dominican Republic. Am J Trop Med Hyg. 2004;71(2):138-143.

22. Halstead SB. Pathogenesis of dengue: challenges to molecular biology. Science. 1988;239(4839):476-481.

23. Idris AN, Baba MM, Thairu Y, Bamidele O. Sero-prevalence of dengue type-3 Virus among patients with febrile illnesses attending a tertiary hospital in Maiduguri, Nigeria. Int J Med Sci. 2013;5(12):560-563.

24. Balogun O. The Federal Capital Territory of Nigeria: A Geography of its Development. Ibadan, Nigeria: Ibadan University Press; 2001.

25. Idoko MO, Ado SA, Umoh VJ. Prevalence of dengue virus and malaria in patients with febrile complaints in Kaduna Metropolis, Nigeria. $\mathrm{Br}$ Microbiol Res J. 2015;8(1):343-347.

26. Baba M, Logue $\mathrm{CH}$, Oderinde B, et al. Evidence of arbovirus coinfection in suspected febrile malaria and typhoid patients in Nigeria. $J$ Infect Dev Ctries 2013;7(1):51-59.

27. Madara AA, Abdulraheem NO. Relative abundance of adult mosquitoes in University of Abuja Main Campus, Abuja FCT, Nigeria. Nig J Parasitol. 2013;34(2):1-5.

28. Dawurung JS, Baba MM, Stephen G, Jonas SC, Bukbuk DN, Dawurung CJ. Serological evidence of acute Dengue virus infection among febrile patients attending Plateau State Specialist hospital Jos, Nigeria. Republic's Opin. 2010;2:71-76.

29. World Health Organization. Dengue guidelines for diagnosis, treatment, prevention and control. 2009;3-64.

30. Bello OA, Aminu M, Jatau ED. Seroprevalence of IgM antibodies to dengue fever virus among patients presenting with symptoms of fever in some hospitals in Kaduna State, Nigeria. Int J Sci Res. 2013;5(3):2319-7064.

31. Gupta E, Dar L, Narang P, Srivastava VK, Broor S. Serodiagnosis of dengue during an outbreak at a tertiary care hospital in Delhi. Indian J Med Res. 2005;121(1):36-38.

32. Kumar A, Rao CR, Pandit V, Shetty S, Bammigatti C, Samarasinghe CM. Clinical manifestations and trend of dengue cases admitted in a tertiary care hospital, Udupi district, Karnataka. Indian J Community Med. 2010;35(3):386-390.

33. Ukey P, Bondade S, Paunipagar P, Powar R, Akulwar S. Study of seroprevalence of dengue fever in central India. Indian J Community Med. 2010;35(4):517-519.

34. Reiskind MH, Baisley KJ, Calampa C, Sharp TW, Watts DM, Wilson ML. Epidemiological and ecological characteristics of past dengue virus infection in Santa Clara, Peru. Trop Med Int Health. 2001;6(3): 212-218.

35. Oladipo EK, Amanetu C, Gbadero TA, Oloke JK. Detectable anti-dengue virus IgM antibodies among healthy individuals in Ogbomoso, Oyo state, Nigeria. Am J Infect Dis. 2014;10(2):64-67. 
HIV/AIDS - Research and Palliative Care

\section{Publish your work in this journal}

HIV/AIDS - Research and Palliative Care is an international, peerreviewed open access journal focusing on advances in research in HIV its clinical progression and management options including antiviral treatment, palliative care and public healthcare policies to control viral spread. The journal is included in PubMed. The manuscript man-
Dovepress

agement system is completely online and includes a very quick and fair peer-review system, which is all easy to use. Visit http://www.dovepress. com/testimonials.php to read real quotes from published authors.

Submit your manuscript here: https://www.dovepress.com/hivaids---research-and-palliative-care-journal 